Brit. J. industr. Med., 1952, 9, 56.

\title{
SALT LOSSES OF MEN WORKING IN HOT ENVIRONMENTS
}

\author{
BY \\ J. S. WEINER and R. E. van HEYNINGEN \\ From the Medical Research Council Climate and Working Efficiency Research Unit, Oxford
}

(RFCEIVED FOR PUBLICATION OCTOBER 31, 1951)

The necessity for an adequate salt intake for people working in hot climates has been recognized for a long time (Moss, 1923). Salt deficiency is with some certainty known to cause heat cramps (Talbott, 1935 ; McCance, 1936 ; Ladell, 1949) and is very likely the cause of lesser degrees of illhealth and inefficiency (Taylor, Henschel, Mickelsen, and Keys, 1943 ; Ladell, Waterlow, and Hudson, 1944). To understand how such ill-effects arise, it is obviously necessary to establish the changes in salt metabolism associated with sweating at high temperatures. In reviews of this matter Ladell (1945) and Robinson (1949) have pointed to the confusion in the literature regarding the exact effects of dietary chloride and acclimatization on the chloride content of the sweat. The recent experiments of Conn and Johnston (1944; Conn, Johnston, and Louis, 1946) have thrown much light on this problem. This work indicates that when the salt loss during exposure to heat is greater than the dietary supply, the " negative " balance may only be temporary; a restriction in both sweat and urine chloride output takes place so that after some days the salt deficit is made good and the total salt output is readjusted to the level of intake. Conn's work is important in showing that balance is possible at levels of salt intake even as low as $6 \mathrm{~g}$. per day for men sweating 5-6 kg. a day. Unfortunately, this, as well as earlier work, may give the impression that this restriction in salt loss is necessarily or invariably a part of the process of acclimatization to heat, whereas in logical extension of Conn's findings one would expect no decrease in sweat chloride on a sufficiently high salt intake. The sweat chloride content on higher salt diets during the acclimatization period seems not as yet to have been investigated in experiments like those of Conn in which the subjects lived continuously in the heat. In the earlier work of Black, McCance, and Young
(1944), however, in which recumbent individuals were exposed daily for short periods in a radiant heat bath, a decrease in sweat chloride output did not, in fact, occur on a high salt diet whereas on a low level of intake a decrease took place.

The experiments reported in this paper are similar to those of McCance (1936) and Black, McCance, and Young (1944), in that they involve short periods of exposure to heat. They were carried out on working subjects exposed to strictly standardized conditions of work. When this investigation was nearly completed, papers by Robinson, Kincaid, and Rhamy (1950) appeared in which they reported results with which those of the present experiments are in substantial accord. It seems useful to record our results, for in addition to confirmation of an important physiological response to hot climates, they are concerned also with another aspect of this problem. In our experiments chloride analysis was made not only of the body sweat from the general body surface but also on sweat collected in arm bags. The difference in the composition between the sweat from these two collections helps to explain some of the confusion referred to by Robinson (1949) and Ladell (1945). Finally, a separate series of experiments on unacclimatized persons is presented because of its bearing on the "salt conserving" responses of the body at high temperatures.

\section{Methods}

Two series of experiments are reported, the first on subjects during acclimatization to heat, the second on unacclimatized subjects. Certain subsidiary experiments are referred to in the text.

Sweat Composition in Relation to Dietary Chloride During Acclimatization.-The five subjects, C, D, N, $\mathrm{Br}$, and $\mathrm{Ba}$ were acclimatized to heat by norking nude in the hot room for two hours on five or six days a week for two or three weeks. All except $\mathrm{Br}$ performed four 
30-minute cycles, each of 20 minutes' work (step climbing, $1 \mathrm{ft}$. high, 12 times a minute), followed by 10 minutes rest; $\mathrm{Br}$ completed only three cycles. The five subjects were exposed to dry bulb $46 \cdot 1^{\circ} \mathrm{C}$., wet bulb $29.4^{\circ} \mathrm{C}$., relative humidity $30 \%$, air movement $50 \mathrm{ft} . / \mathrm{min}$. The subjects (except $\mathrm{Ba}$ ) ate their normal diet with the addition of $10 \mathrm{~g}$. of $\mathrm{NaCl}(171 \mathrm{mEq}$./ chloride) after each hot room exposure.

The experiment on subject $\mathrm{Ba}$ was carried out in three stages. The first stage occupied seven days (Sunday to Saturday inclusive) when Ba ate his normal diet supplemented by $8 \mathrm{~g}$. $\mathrm{NaCl}(137 \mathrm{mEq}$./chloride) daily and spent two hours in the hot room every day except Sunday. The second stage took six days (Sunday to Friday inclusive) when he took a diet deficient in salt, containing about $16 \mathrm{mEq}$./chloride a day (less than 1 g. $\mathrm{NaCl}$ ). He was in the hot room on five days, Monday to Friday inclusive. For the third stage, the next four days (Saturday to Tuesday inclusive), he resumed his normal diet supplemented by $8 \mathrm{~g} . \mathrm{NaCl}$ (137 mEq./chloride) daily. He worked in the hot room on Monday and Tuesday.

Urine collections (24-hourly) were made daily, starting each morning from the time when the subject entered the hot room. They were analysed for chloride. Faecal loss of chloride and that lost in the sweat when the subject was not in the hot room were neglected.

Partition of Chloride between Sweat and Urine in Unacclimatized Subjects.-Two subjects (Mol and Mac) each worked for two hours (i.e., four cycles) in eight different environments covering a range of temperature from $37 \cdot 2^{\circ} \mathrm{C}$. to $44 \cdot 4^{\circ} \mathrm{C}$. at $40 \%$ room heat, and from $27 \cdot 7^{\circ} \mathrm{C}$. to $33 \cdot 3^{\circ} \mathrm{C}$. at approximately $100 \%$ room heat. To keep the subjects unacclimatized to heat as far as possible they were exposed only three times a fortnight. Each subject ate $5 \mathrm{~g}$. salt ( $86 \mathrm{mEq}$.) after each exposure. On the days on which the subject was in the hot room 24-hour collections of urine were made from the time he entered the hot room until the same time next day; the collection made while he was actually in the hot room was kept separate from the rest; both were analysed for chloride. The total sweat output was also analysed for chloride. Twenty-four-hour urine collections were made on the days preceding those in the hot room, thus giving an estimate of the total normal output (and therefore an indication of the intake) of chloride. It was not feasible to control the diet of these subjects. On the day after an exposure (as soon as the 24-hour urine collection had been completed) the subject took salt by mouth to compensate for that lost in the sweat.

Sweat Composition.-Before each experiment the subjects had a shower and were washed with a jet of distilled water. Arm sweat was collected in a dry oilskin irrigation envelope which had completely but loosely encased the whole of one arm and hand and fitted firmly around the top of the arm just below the axilla. The arm was well washed with distilled water and dried before the bag was put on. Sweat was drained through an outlet at the bottom of the bag every half hour. The sweat from the rest of the body surface was collected in a large bath in which the subject spent the whole of the time he was in the hot room. The sides of the bath came up to his shoulders so that no sweat splashed outside. There was a slope towards one end so that the sweat and subsequent washings of body and bath could be drained into a weighed bucket.

At the end of the experiment the room was cooled down rapidly to prevent further sweating. The arm bag was removed and the arm washed with distilled water until the washings were chloride-free. The combined washings and the serial arm collections were analysed for chloride. The volume of sweat adhering to the arm before the final washing was taken to be $x y / z$ where $x$ is the volume of diluted sweat after it was washed down, $y$ the chloride concentration of this diluted sweat, and $z$ the concentration of the last collection. It is assumed that the concentration of the final adherent sweat is the same as that in the last collection.

The rest of the body surface was washed down with distilled water, and the subject then left the bath and was weighed. The sides of the bath were washed down with distilled water until the washings were chloride-free, and the sweat and washings from the body (about 51 .) collected in the bucket which was then re-weighed. The subject was then dried by rubbing down with absorbent (salt-free) paper which was then put in with the washings in the bucket. The subject was then re-weighed. The chloride concentration of the diluted sweat was determined. The corresponding value for undiluted sweat was calculated by multiplying the values by the factor $\left[\frac{\text { weight of diluted sweat }}{\text { total sweat loss (less arm bag sweat) }}\right]$ From the serial sweat collections and the final arm washing the total output and average composition of arm bag sweat over the whole sweating period was also calculated.

The actual length of time over which sweat was collected did not differ by more than a few minutes from day to day (125 minutes for the four-cycle experiments and 95 minutes for the three-cycle experiments). After the concentrations had been calculated, the volumes of the arm and body sweat were corrected to be equivalent to the same length of time each day (125 minutes or 95 minutes).

Sweat Loss.-Sweat loss was calculated from the loss in weight, allowing for water drunk, urine passed, and respiratory loss of water. It was necessary to apply this last correction in these experiments because of the low rate of sweating at the lower environmental temperatures. The correction, calculated from the ventilation rate of the subject and the relative humidity of the surroundings, varied from 14 to $70 \mathrm{~g}$. over the twohour exposure; it accounted for about $25 \%$ of the uncorrected sweat loss at the lowest ambient temperatures and about $2 \%$ at the highest ambient temperatures.

Skin Temperatures.-In subjects $\mathrm{N}$ and $\mathrm{Ba}$ skin temperatures were measured on 11 spots of the body, and on the upper arm, forearm, and wrist within the bag. The 11 spots on the body were : forehead, wrist, forearm, upper arm, chest, scapula, kidney, outer 
surface of the thigh, medial surface of the thigh, calf, and toe. The measurements, which were taken just before the man started and at the end of each spell of work, were made by means of a $\mathbf{4 0}$ gauge copper constantan thermocouple mounted on a small plastic holder and they were recorded by a potentiometer and a Tinsley 2 -second galvanometer. Theaveragesurfacetemperature was obtained from the 11 skin temperatures by weighting according to the proportion of the surface area represented by each thermocouple (Belding, Darling, Griffin, Robinson, and Turrell, 1945). An average of the three values on each arm (upper, forearm, hand) was also calculated. The five values for the body skin temperatures thus obtained for each experiment (initial and after the four work periods) were averaged to give the average body skin temperature of the experiment. In this average rather too much weight is probably given to the initial low temperature, since little sweat is produced from an unacclimatized subject until the skin temperature is raised considerably.

Rectal Temperature and Pulse Rate.-Rectal temperature (clinical thermometer inserted for two minutes) and pulse rate (counted for half a minute with the subject in a standing position) were taken initially and immediately after each work period.

\section{Results}

Observations During Acclimatization.--In all subjects the usual phenomena associated with acclimatization were observed. As the days passed the sweat rate increased and the final rectal temperature decreased (Fig. 1); moreover, as Table 1 shows, in subjects $\mathrm{N}$ and $\mathrm{Ba}$ (days 1 to 6) the average skin temperature of the general body surface as well as that within the arm bag fell during acclimatization. These accompaniments of acclimatization are now well established(Newburgh, 1949). Robinson, Turrell, Belding, and Horvath (1943) showed, and we have frequently confirmed in experiments carried out in the climatic chamber in Oxford, that about $80 \%$ of the changes in sweating, body temperature, and pulse rate occurred in the first seven days of exposure. It is obvious therefore that the first week or two of daily exposure to heat are the crucial ones for examining sweat for changes brought about by acclimatization. It will be noted (Fig. 2) that during the first week of acclimatization on a high salt diet Ba's weight (as measured in the morning before entering the hot room) increased from 76.4 to $77.5 \mathrm{~kg}$. This may well be due to the rapid increase of blood volume reported by Bazett, Sunderman, Doupe, and Scott (1940) in confirmation of a phenomenon first noted by Barcroft, Meakins, Davie;, Scott, and Fetter (1923).

During the week on a low salt diet Ba's weight fell by $3.5 \mathrm{~kg}$. to $74.0 \mathrm{~kg}$., and at the same time his acclimatization appeared to be impeded in so far

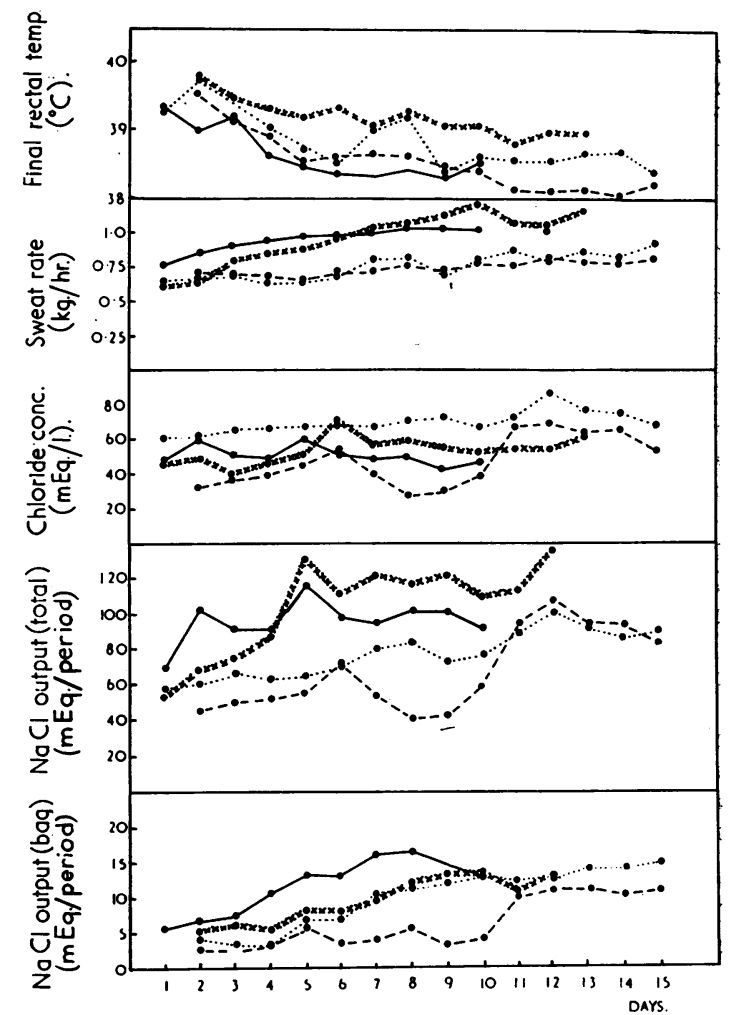

Fig. 1.-(a) Final rectal temperature, (b) sweat rate, (c) chloride concentration of body sweat, $(d) \mathrm{NaCl}$ output in body sweat, (e) $\mathrm{NaCl}$ output in arm bag sweat on successive days of acclimatization.

Subject $\mathbf{N}=$ xxxxx. $\quad \begin{gathered}\text { Subject } \mathbf{B r}=\ldots \ldots \\ \text { Subject } \mathrm{C}=\ldots\end{gathered}$

as the average rectal temperatures, skin temperatures, and pulse rate were higher than in the preceding week (Table 1), and his general condition was poorer. Ordinarily a most energetic person, the subject was now apathetic, complained of fatigue, and, on the last days, of headache during work. The sweat rate nevertheless continued to increase slowly (Table 1 and Fig. 2). When salt was replaced in the diet the rectal temperature fell below the level of the two preceding weeks and the skin temperature also decreased; sweat loss still continued to increase. These findings support those of Adolph (1947) who states that the loss of salt and body fluid interferes with the temperature regulation of men working in the heat, and are confirmed in detail by Robinson and others (1950) who report that " the men's rectal temperature increased during the second and third days on the low salt intake $;. .$. as the salt deficit was restored, temperature regulation was restored again; . . . their heart rates during work in the heat were raised during the 
TABLE I

EFFECT OF ACCLIMATIZATION TO HEAT (D.B. $46 \cdot 1^{\circ}$ C., W.B. $29 \cdot 4^{\circ}$ C.) On BA AND N*

\begin{tabular}{|c|c|c|c|c|c|c|c|c|c|c|c|c|c|c|c|c|}
\hline Day & 1 & 2 & 3 & 4 & 5 & 6 & 7 & 8 & 9 & 10 & 11 & 12 & 13 & 14 & 15 & 16 \\
\hline & Mon. & Tues. & Wed. & Thur. & Fri. & Sat. & Sun. & Mon. & Tues. & Wed. & Thur. & Fri. & Sat. & Sun. & Mon. & Tues. \\
\hline $\begin{array}{c}\text { Average rectal } \\
\text { temperature }\end{array}$ & $38 \cdot 7$ & $38 \cdot 3$ & $38 \cdot 3$ & $38 \cdot 2$ & $38 \cdot 4$ & $38 \cdot 2$ & 一 & $\begin{array}{r}\text { Subje } \\
\mid 38 \cdot 6\end{array}$ & \begin{tabular}{|} 
ct $B a$ \\
$38 \cdot 5$
\end{tabular} & $38 \cdot 6$ & $38 \cdot 2$ & - & - & - & $37 \cdot 8$ & $38 \cdot 1$ \\
\hline Sweat rate & $7 \cdot 8$ & $8 \cdot 8$ & $9 \cdot 9$ & $10 \cdot 4$ & $12 \cdot 1$ & $12 \cdot 3$ & - & $13 \cdot 1$ & $13 \cdot 4$ & 13.9 & $13 \cdot 1$ & - & - & - & $14 \cdot 1$ & $15 \cdot 6$ \\
\hline Final pulse rate & 一 & - & 136 & 126 & 134 & 138 & - & 156 & 156 & 168 & 150 & - & - & - & 130 & 136 \\
\hline $\begin{array}{l}\text { Average body } \\
\text { skin tem- } \\
\text { perature }\end{array}$ & $37 \cdot 3$ & 一 & $37 \cdot 0$ & $36 \cdot 9$ & $36 \cdot 9$ & $36 \cdot 1$ & - & $36 \cdot 5$ & $36 \cdot 4$ & $36 \cdot 5$ & $36 \cdot 9$ & 一 & - & - & $36 \cdot 0$ & $36 \cdot 2$ \\
\hline $\begin{array}{l}\text { Average } \\
\text { skin } \\
\text { perature }\end{array}$ tem- & $38 \cdot 7$ & - & $38 \cdot 0$ & $38 \cdot 0$ & $37 \cdot 9$ & $36 \cdot 9$ & - & $38 \cdot 1$ & $37 \cdot 0$ & $38 \cdot 2$ & $39 \cdot 9$ & - & - & - & $37 \cdot 5$ & $37 \cdot 9$ \\
\hline $\begin{array}{c}\text { Average rectal } \\
\text { temperature }\end{array}$ & $38 \cdot 4$ & $37 \cdot 9$ & $38 \cdot 2$ & $38 \cdot 4$ & $37 \cdot 9$ & - & 一 & $\begin{array}{l}\text { Suhje } \\
38 \cdot 1\end{array}$ & $\begin{array}{l}\text { ect } N \\
37 \cdot 9\end{array}$ & - & 一 & - & 一 & 一 & 一 & - \\
\hline Sweat rate & $10 \cdot 2$ & $11 \cdot 0$ & $12 \cdot 3$ & $15 \cdot 0$ & $14 \cdot 4$ & - & - & $15 \cdot 9$ & $14 \cdot 9$ & 一 & 一 & - & - & - & 一 & - \\
\hline Final pulse rate & 160 & 152 & 152 & 148 & 152 & - & - & 140 & 128 & - & - & - & - & - & - & - \\
\hline $\begin{array}{ll}\text { Average body } \\
\text { skin } \\
\text { perature }\end{array}$ & $36 \cdot 5$ & $35 \cdot 9$ & $35 \cdot 9$ & $36 \cdot 3$ & $35 \cdot 9$ & - & - & $36 \cdot 0$ & $35 \cdot 7$ & - & - & - & - & - & 一 & - \\
\hline
\end{tabular}

*Temperatures are measured in ${ }^{\circ} \mathrm{C}$, sweat rates in $\mathrm{ml} . / \mathrm{min}$., and pulse rate in beats/min. On Days 7-12 Ba was on a low salt diet.

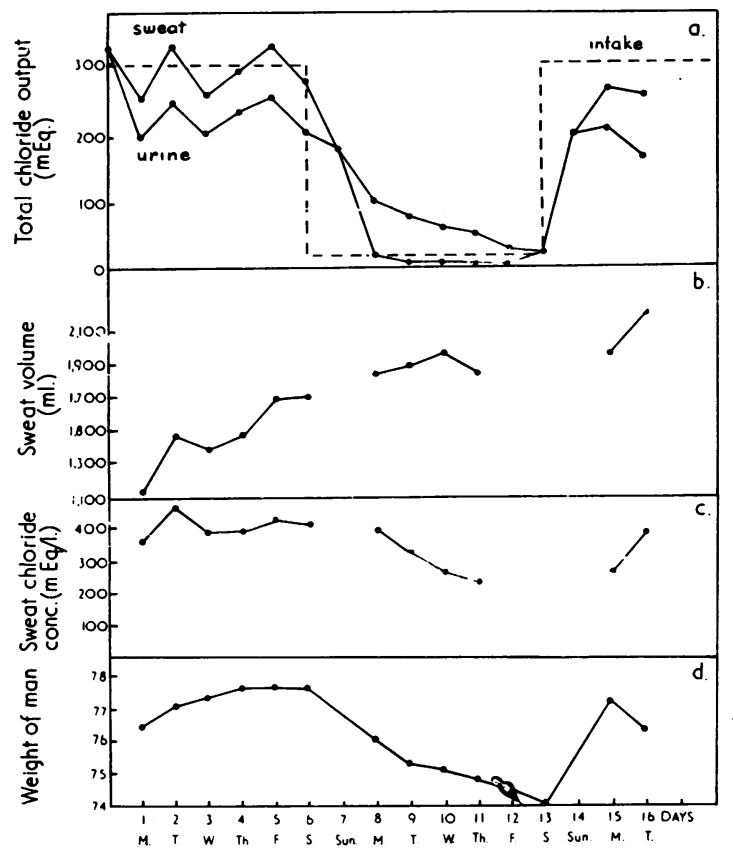

period of deficit and then lowered again after the salt intake was increased." It seems certain that salt deficit can interfere with the process of acclimatization.

General Body Sweat.-When acclimatization was induced on a high salt diet the chloride concentration showed no sustained change (Fig. 1); the level fluctuated from day to day but there was no suggestion of any decrease in chloride concentration. This is in accordance with the findings of Robinson and others. In view of the progressive increase in sweat loss, the total salt loss in fact increased (Fig. 1), so that on a high salt diet no conservation or restriction of salt by the sweat gland occurs during acclimatization as already pointed out by Black, McCance, and Young (1944).

Fig. 2.--In subject $\mathrm{Ba},(a)$ total chloride output in urine, and in sweat and urine; (b) total volume of body sweat produced in two hours ; $(c)$ chloride concentration of this sweat ; and $(d)$ the morning weight of subject daily throughout acclimatization to heat. The intake of chloride in the diet was about $300 \mathrm{mEq}$. on days 0 to 6 inclusive, and 13 to 16 inclusive : on days 7 to 12 it was $16 \mathrm{mEq}$. 
The results of the experiment on subject $\mathrm{Ba}$ are summarized in Fig. 2. During the first week (days 1 to 6) chloride in the sweat remained fairly constant. The total salt output in sweat plus urine also remained fairly constant while the sweat rate increased from day to day. On the first day of exposure in the next week, that is the second day on which the diet was low in chloride, there was no reduction in either concentration or total output of sweat chloride, but the output of chloride in the urine was greatly reduced. On the following three days, however, the chloride level in the sweat fell steadily day by day while the output in the urine became negligible. (On Friday, day 12, the last day on which the low chloride diet was eaten, the subject worked in the hot room at a lower environmental temperature ; the chloride concentration of the sweat is omitted as it is not comparable with the rest.)

On the Monday of the third week (day 15), the third day that the supplemented normal diet had been resumed, the sweat chloride was still low, but on the following day it had returned to its former level. The overall output of chloride in sweat plus urine was only a little below the probable level of intake on this day. The findings of Robinson and others are entirely in agreement with these results in showing that a decrease in chloride concentration may be induced late in the acclimatization period, and is not an essential part of it but depends on the level of salt intake.

Arm Bag Sweat.-When the chloride concentration and output are followed during acclimatization in sweat collected from arm bags, two peculiarities are noted, which we attribute to the presence of the bag (van Heyningen, 1951). First, the output of sweat in the arm bag increases as it does in general body sweat, but the increase is relatively far greater. The total sweat rate of all the four subjects on a high salt intake had increased by the tenth day of exposure by increments varying from $21 \%$ to $98 \%$ while the sweat rate from the arm had increased by increments varying from $235 \%$ to $288 \%$. As shown in Fig 3 on four subjects, the ratio of volume of body sweat to volume of arm sweat decreased over the same period from between 30 and 50 to about 15 , a value close to that arrived at indirectly from an analysis of the regional distribution of sweating (Weiner, 1945). The fifth subject, $\mathrm{Ba}$, gave a very similar result. Secondly (Fig. 4) the chloride concentration of arm bag sweat, as of the other constituents, lactate and urea, (Weiner and van Heyningen, 1949) falls with acclimatization even on a high salt diet, whereas the general body sweat shows no trend in this respect. Nevertheless the daily output of salt from the arm bag, like that from the general body surface,

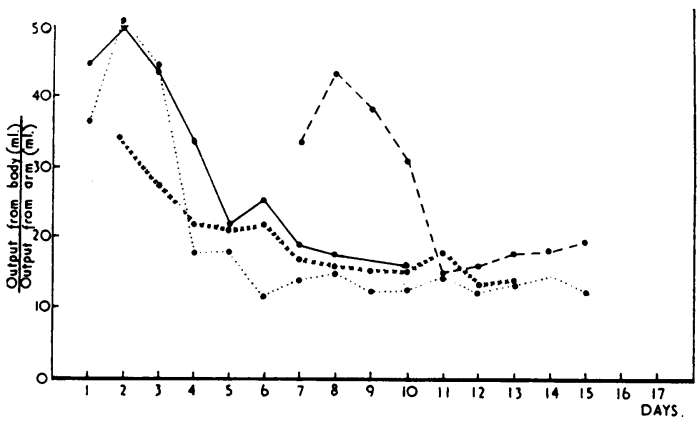

Fig. 3.-The ratio on successive days of acclimatization. Total volume output from body: total volume output from arm. Subject $\mathbf{N}=\operatorname{xxxxx} . \quad$ Subject $\mathrm{Br}=\ldots$. Subject $\mathrm{D}=\ldots \ldots$ Subject $\mathrm{C}=$

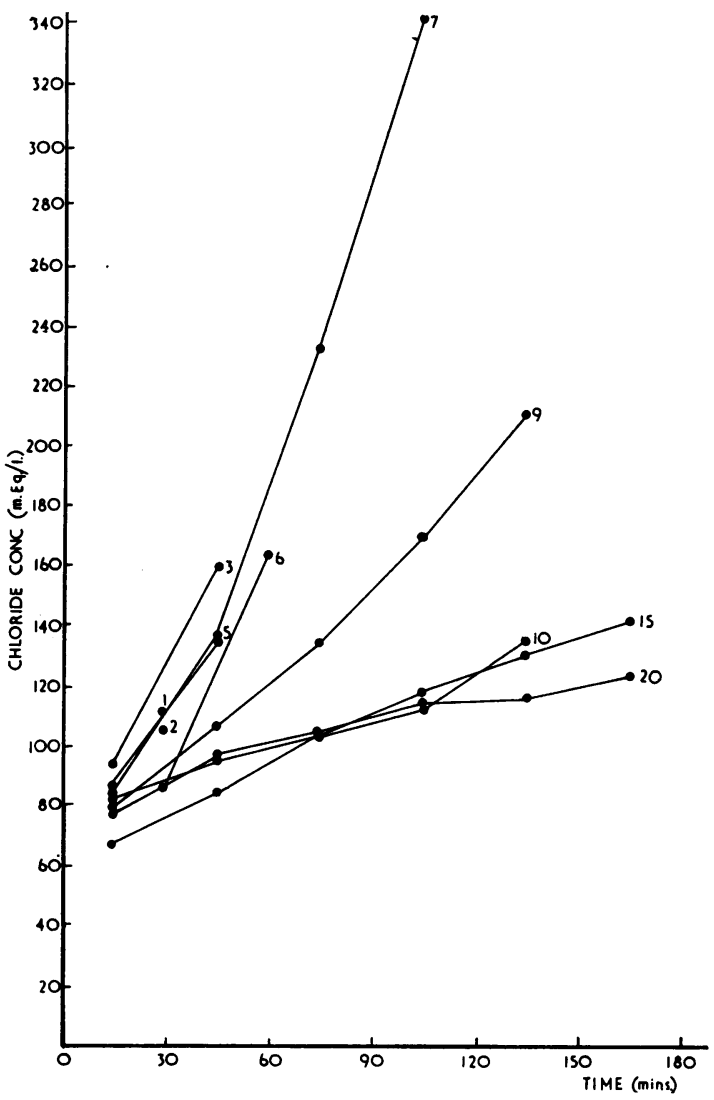

Fig. 4.- In subject $\mathrm{Br}$ change in chloride concentration of arm bag sweat during exposure throughout acclimatization. The numbers on the curves are the serial days of exposure. The subject's diet was supplemented with $\mathrm{NaCl}$ daily. 
does not fall but increases (Fig. 1). The fall in chloride concentration in arm bag sweat is due solely to the very large increase in output of water within the arm bag during the acclimatization period. When the subject goes on to a low chloride intake the concentration of salt in arm bag sweat does, in fact, fall, as Ladell (1945) observed. A fall in concentration of arm bag sweat is therefore found both as a result of acclimatization and of low salt intake. Although the fall in concentration on a high salt intake does not indicate a conservation of salt, it appears to run more or less parallel to the acclimatization process. This is well illustrated by experiments (Table 2 ) in which a comparison sweat, the two and a half hour loss of chloride (sweat plus urine) was on an average much lower than that on the control days when there was no exposure to heat. In Mol, one of the subjects, the average chloride output in the urine on the eight control days was $224.4 \mathrm{mEq}$. ; on the 10 days on which he was in the hot room the average output was $124.7 \mathrm{mEq}$. in sweat and urine. In Mac, the second subject, the average chloride output on the eight control days was $244.4 \mathrm{mEq}$. and on the eight days on which he went in the hot room it was $174.2 \mathrm{mEq}$.

A $t$ test indicates that in subject Mol the difference between the means of the two series is highly

TABLE 2

COMPARISON OF ARM BAG SWEAT IN SUBJECT H IN VARIOUS ENVIRONMENTS BEFORE AND AFTER ACCLIMATIZATION

\begin{tabular}{|c|c|c|c|c|c|c|c|c|}
\hline \multirow{2}{*}{\multicolumn{3}{|c|}{ Date (1948) }} & \multicolumn{3}{|c|}{ Environments } & \multirow{2}{*}{$\begin{array}{l}\text { Sweat } \\
\text { Chloride } \\
\text { (mEq./l.) }\end{array}$} & \multirow{2}{*}{$\begin{array}{c}\text { Rectal } \\
\text { Temperature } \\
\text { (Rise in } \\
\left.2 \frac{1}{2} \text { hr. }{ }^{\circ} \mathrm{C} .\right)\end{array}$} & \multirow{2}{*}{$\begin{array}{c}\text { Overall } \\
\text { Sweat } \\
\text { Rate } \\
\text { (ml./min.) }\end{array}$} \\
\hline & & & $\begin{array}{l}\text { D.B. } \\
\left({ }^{\circ} \mathrm{C} .\right)\end{array}$ & $\begin{array}{l}\text { W.B. } \\
\left({ }^{\circ} \mathrm{C} .\right)\end{array}$ & $\begin{array}{c}\text { A.M. } \\
\text { (ft./min.) }\end{array}$ & & & \\
\hline $\begin{array}{l}\text { July } 13 \\
\text { Sept. } 15\end{array}$ & $\begin{array}{l}\cdots \\
\cdots\end{array}$ & $\begin{array}{l}\cdots \\
\cdots\end{array}$ & $\begin{array}{c}37 \cdot 5 \\
\ldots\end{array}$ & $\begin{array}{c}32 \cdot 0 \\
\ldots\end{array}$ & $\begin{array}{l}75 \\
\cdots\end{array}$ & $\begin{array}{l}155 \\
148\end{array}$ & $\begin{array}{l}1.4 \\
0.8\end{array}$ & $\begin{array}{r}7 \cdot 5 \\
21 \cdot 3\end{array}$ \\
\hline $\begin{array}{l}\text { July } 23 \\
\text { Oct. } 1\end{array}$ & $\begin{array}{l}\cdots \\
\cdots\end{array}$ & $\begin{array}{l}\cdots \\
\cdots\end{array}$ & $\begin{array}{c}51 \cdot 5 \\
\ldots\end{array}$ & $\begin{array}{c}27 \cdot 5 \\
\ldots\end{array}$ & $\begin{array}{c}100 \\
\ldots\end{array}$ & $\begin{array}{l}153 \\
119\end{array}$ & $\begin{array}{l}1 \cdot 2 \\
0 \cdot 2\end{array}$ & $\begin{array}{l}14 \cdot 9 \\
15 \cdot 5\end{array}$ \\
\hline $\begin{array}{l}\text { July } 27 \\
\text { Sept. } 27\end{array}$ & $\begin{array}{l}\cdots \\
\cdots\end{array}$ & $\begin{array}{l}\cdots \\
\cdots\end{array}$ & $\begin{array}{c}32 \cdot 0 \\
\ldots\end{array}$ & $\begin{array}{c}32 \cdot 0 \\
\ldots\end{array}$ & $\begin{array}{c}135 \\
\cdots\end{array}$ & $\begin{array}{r}111 \\
99\end{array}$ & $\begin{array}{l}0 \cdot 3 \\
0 \cdot 2\end{array}$ & $\begin{array}{l}7 \cdot 6 \\
8 \cdot 5\end{array}$ \\
\hline $\begin{array}{l}\text { July } 29 \\
\text { Sept. } 30\end{array}$ & $\begin{array}{l}\cdots \\
\cdots\end{array}$ & $\begin{array}{l}. \\
\cdots\end{array}$ & $\begin{array}{c}43 \cdot 5 \\
\ldots\end{array}$ & $\begin{array}{c}31 \cdot 0 \\
\ldots\end{array}$ & $\begin{array}{l}20 \\
\cdots\end{array}$ & $\begin{array}{l}178 \\
113\end{array}$ & $\begin{array}{l}1 \cdot 6 \\
0 \cdot 3\end{array}$ & $\begin{array}{l}19 \cdot 7 \\
13.3\end{array}$ \\
\hline $\begin{array}{l}\text { Aug. } 5 \\
\text { Sept. } 14\end{array}$ & $\begin{array}{l}\cdots \\
\cdots\end{array}$ & $\begin{array}{l}\ldots \\
\cdots\end{array}$ & $\begin{array}{c}35 \cdot 0 \\
\ldots\end{array}$ & $\begin{array}{c}27 \cdot 0 \\
\ldots\end{array}$ & $\begin{array}{l}75 \\
\cdots\end{array}$ & $\begin{array}{r}131 \\
92\end{array}$ & $\begin{array}{l}0.2 \\
0.0\end{array}$ & $\begin{array}{l}6 \cdot 8 \\
7 \cdot 5\end{array}$ \\
\hline $\begin{array}{l}\text { July } 15 \\
\text { Sept. } 24\end{array}$ & $\begin{array}{l}\cdots \\
\ldots\end{array}$ & $\begin{array}{l}. \\
\ldots\end{array}$ & $\begin{array}{c}43.5 \\
\ldots\end{array}$ & $\begin{array}{c}31 \cdot 0 \\
\ldots\end{array}$ & $\begin{array}{l}50 \\
\cdots\end{array}$ & $\begin{array}{l}163 \\
124\end{array}$ & $\begin{array}{l}2 \cdot 5 \\
0 \cdot 3\end{array}$ & $\begin{array}{l}11 \cdot 2 \\
15 \cdot 7\end{array}$ \\
\hline
\end{tabular}

of the composition of sweat, obtained in six different thermal environments before and again after acclimatization, was made on a subject, $H$. The six initial exposures were made at the rate of only two a week to ensure as far as possible that the subject remained unacclimatized to heat. He was acclimatized by repeated exposure between August 23 and September 10 . Table 2 shows, in conformity with the results already described, that the "post-acclimatization" exposures always yielded sweat of a lower chloride content. The overall sweat rate was increased in five cases out of six and the rise in rectal temperature was always decreased.

Salt Loss of Unacclimatized Subjects.-Table 3 gives the results for two subjects. The total chloride loss in the sweat increased as the conditions became more severe. In spite of the loss of chloride in the significant, $\mathbf{P}=\mathbf{0 . 0 0 1}$ (difference between means $=$ 99.7, degrees of freedom $=16, t=5 \cdot 25$ ). For subject Mac, $P$ is just below the $5 \%$ level of significance (difference between means $=70 \cdot 2$, degrees of freedom $=14, t=2.05$ ). These results show that the total loss of chloride on days on which sweating occurs did not exceed the loss on days when no heat exposure took place, and in the case of subject Mol it was decidedly less. In subject Mac, although a reduction is also present, it is statistically barely significant. In both subjects it is clear that the kidney restriction has been sufficient to compensate for the sweat salt loss.

\section{Discussion}

The foregoing experiments are in agreement with those of Black and others (1944), Conn and others (1946), and Robinson and others (1950) in affirming that a reduction in the chloride concentration (and 
output) of body sweat occurs only when the intake of dietary salt is insufficient to prevent the occurrence of a negative salt balance induced by sweating. It is very likely that this process of adjustment underlay the original observations of the phenomenon by Dill, Jones, Edwards, and Oberg (1933). The " salt conservation" response is not a necessary part of the acclimatization process; it may be induced after the individual has been in the heat for shorter or longer periods, as in our experiments, and in those of Robinson and others or, as has been shown, it may be entirely absent in the acclimatization period if the salt intake is maintained at a high level. The fact that on a high salt diet the sweat chloride concentration in arm bag sweat (unlike general body sweat) falls, is not an indication of salt conservation. As we have shown, the salt loss does not decrease. The fall in arm bag sweat concentration is bound up with the acclimatization process itself since it is attributable to the very large increase in sweat loss within the arm bag.

The reason for the relatively greater increase in output of sweat within the arm bag during acclimatization is not known, but must, in some way, be due to the higher temperature and humidity therein.

The response to a salt deficit by the sweating man leading to the re-establishment of salt balance has been analysed in some detail by Conn (1949a). When his subjects, who were on a constant diet containing 14.5 g. $\mathrm{NaCl}(248 \mathrm{mEq}$.) a day, were first introduced into the hot room, there was a sharp fall in the urinary loss of chloride. This was followed on the next day by a sharp fall in the chloride concentration of sweat, the total loss of salt by this route being greatly reduced. The urinary excretion then gradually rose until an equilibrium between intake and losses in sweat and urine was established after about five days. On a daily intake as low as $52 \mathrm{mEq}$. Robinson's subject was near to establishing an equilibrium on the fourth day. Whether our subject Ba (Fig. 2) on a still lower intake (16 mEq.) could have done likewise is not certain ; it would have required a negligible output of chloride in the urine and a sweat chloride concentration of about $7 \mathrm{mEq}$. $/ 1$. Sweat of nearly this dilution has been reported by both Conn and Robinson. By the fourth day the chloride concentration had not in our subject fallen below $20 \mathrm{mEq}$./1., though the daily deficit was progressively lessening (Fig. 2). The total drain of salt from the body over these four days amounted to about $300 \mathrm{mEq}$. of $\mathrm{NaCl}$. As McCance (1936) showed, salt deficiency is accompanied in its first stages by a corresponding water loss, the effect of which is to preserve for the time being the normal osmotic pressure.

In combating a threatened salt deficiency the response of the kidney is extremely prompt and precedes that of the sweat gland, as shown by Conn (1949a). The prompt response of the kidney in restricting salt loss seems to us, on the basis of the results in our section on the partition of chloride between sweat and urine in unacclimatized subjects, to be a reaction of exposure to heat per se. These experiments show that the occasional exposure to heat of unacclimatized subjects, with its consequent loss of chloride in the sweat, brings about a compensatory reduction of urinary chloride so great that the total loss of chloride may be actually less on these days than on the days when the subject was not exposed to heat (Table 3). Furthermore, this compensatory response demonstrates that when subjects were acclimatized to heat on a high salt diet there was no possibility of a negative balance occurring to stimulate the reduction of sweat chloride concentration. The operation of such a " chloride saving mechanism " was postulated by Lee and Mulder (1935) but further experiments seemed to Lee, Murray, Simmonds, and Atherton (1941) to throw some doubt on its existence. Their subjects spent six to seven hours daily in the hot room, but the chloride excretion during the remainder of the 24 hours, when the subjects were not in the hot room, was not measured; it is during this time that the sparing mechanism operated in the present experiments. As in Lee's experiments, the volumes of urine excreted in the hot room were too low to determine at what stage the sparing mechanism began to operate. It was during the remainder of the 24 hours after the subject had left the hot room that the reduction in urinary chloride output was manifested.

The regulatory processes underlying these kidney and sweat gland responses are not yet clearly established. Current hypothesis favours the involvement of the adrenal cortex, and this has received support from experiments by Conn and others (1946) and Robinson (1949) who have shown that desoxycorticosterone acetate reduces the chloride of general body sweat, as suggested earlier by Laddell (1945) and Moreira, Johnson, Forbes, and Consolazio (1945) using arm bag samples. Conn (1949 $\mathrm{a}$ and b) believes that the adrenal cortex activity is mediated through the adreno-corticotrophic hormone of the pituitary.

During a period of salt deficit in the heat the subject experiences not only an interference with heat regulation, as intimated above, but also subjective distress, despite preceding acclimatization. These reactions were noticeable in our study and 
TABLE 3

SALT LOSS OF TWO UNACCLIMATIZED SUBJECTS

\begin{tabular}{|c|c|c|c|c|c|c|c|}
\hline \multicolumn{3}{|c|}{ Environment } & \multicolumn{4}{|c|}{$\begin{array}{l}\text { Chloride (mEq.) Loss } \\
\text { During and After Hot Room }\end{array}$} & \multirow{2}{*}{ 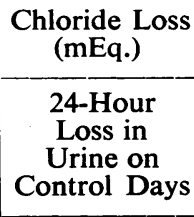 } \\
\hline $\begin{array}{l}\text { D.B. } \\
\left({ }^{\circ} \mathrm{C} .\right)\end{array}$ & $\begin{array}{l}\text { W.B. } \\
\left({ }^{\circ} \mathbf{C} .\right)\end{array}$ & $\underset{(\%)}{\text { R.H. }}$ & Sweat & $\begin{array}{l}\text { Urine } \\
\text { Passed } \\
\text { in Hot } \\
\text { Room }\end{array}$ & $\begin{array}{l}\text { 24-Hour } \\
\text { Loss in } \\
\text { Urine }\end{array}$ & $\begin{array}{l}\text { 24-Hour } \\
\text { Loss in } \\
\text { Sweat and } \\
\text { Urine }\end{array}$ & \\
\hline $\begin{array}{l}23 \cdot 8 \\
30 \cdot 5 \\
34 \cdot 4 \\
27 \cdot 7 \\
30 \cdot 5 \\
37 \cdot 2 \\
38 \cdot 8 \\
38 \cdot 8 \\
33 \cdot 0 \\
37 \cdot 8\end{array}$ & $\begin{array}{l}23 \cdot 8 \\
21 \cdot 1 \\
23 \cdot 8 \\
27 \cdot 7 \\
30 \cdot 5 \\
26 \cdot 1 \\
27 \cdot 7 \\
27 \cdot 7 \\
33 \cdot 0 \\
34 \cdot 5\end{array}$ & $\begin{array}{r}100 \\
40 \\
40 \\
100 \\
100 \\
40 \\
40 \\
40 \\
100 \\
80\end{array}$ & $\begin{array}{r}1 \cdot 9 \\
6 \cdot 8 \\
9 \cdot 4 \\
9 \cdot 6 \\
16 \cdot 8 \\
22 \cdot 1 \\
32 \cdot 0 \\
34 \cdot 7 \\
46 \cdot 0 \\
47 \cdot 9\end{array}$ & $\begin{array}{c}\text { lbject } N \\
9 \cdot 6 \\
24 \cdot 3 \\
25 \cdot 5 \\
2 \cdot 6 \\
25 \cdot 0 \\
5 \cdot 1 \\
32 \cdot 2 \\
14 \cdot 2 \\
17 \cdot 8 \\
28 \cdot 7\end{array}$ & $\begin{array}{r}107.2 \\
97.0 \\
67.9 \\
133.9 \\
97.7 \\
83.5 \\
165.7 \\
75.5 \\
135.0 \\
57.5\end{array}$ & $\begin{array}{r}109 \cdot 1 \\
103.8 \\
77 \cdot 3 \\
143.5 \\
114.5 \\
105.6 \\
197.7 \\
110.2 \\
181.0 \\
105.4\end{array}$ & $\begin{array}{c}\text { Mol } \\
183 \\
185 \\
195 \\
195 \\
229 \\
239 \\
272 \\
297 \\
\ldots \\
.\end{array}$ \\
\hline $\begin{array}{l}24 \cdot 4 \\
26 \cdot 1 \\
27 \cdot 7 \\
30 \cdot 5 \\
38 \cdot 8 \\
43 \cdot 3 \\
33 \cdot 0 \\
43 \cdot 3\end{array}$ & $\begin{array}{l}15 \cdot 5 \\
26 \cdot 1 \\
27 \cdot 7 \\
30 \cdot 5 \\
27 \cdot 7 \\
30 \cdot 5 \\
33 \cdot 0 \\
30 \cdot 5\end{array}$ & $\begin{array}{r}40 \\
100 \\
100 \\
100 \\
40 \\
40 \\
100 \\
40\end{array}$ & $\begin{array}{r}2 \cdot 2 \\
2 \cdot 9 \\
5 \cdot 3 \\
14 \cdot 9 \\
34 \cdot 9 \\
62 \cdot 3 \\
77 \cdot 6 \\
81 \cdot 9\end{array}$ & $\begin{array}{c}\text { bject } M \\
48.7 \\
33.8 \\
117.4 \\
29.6 \\
19.6 \\
7.8 \\
10.8 \\
34.7\end{array}$ & $\begin{array}{r}204 \cdot 7 \\
172 \cdot 6 \\
192 \cdot 5 \\
137 \cdot 7 \\
132 \cdot 2 \\
63 \cdot 6 \\
77 \cdot 0 \\
131.0\end{array}$ & $\begin{array}{l}206 \cdot 9 \\
175 \cdot 5 \\
197 \cdot 8 \\
152 \cdot 6 \\
167 \cdot 1 \\
125 \cdot 9 \\
154 \cdot 6 \\
212.9\end{array}$ & $\begin{array}{r}M a c \\
119 \\
195 \\
218 \\
226 \\
227 \\
244 \\
287 \\
439\end{array}$ \\
\hline
\end{tabular}

Sweat and urine were collected over two hours in the hot room. Urine was collected over the following 22 hours.

in that by Robinson; the latter found that a return to salt improves the individual's condition noticeably. There is a strong presumption from McCance's studies (McCance, 1936; Black, McCance, and Young, 1944) that the distress and inefficiency are closely bound up with both osmotic and circulatory disturbances. During the period of "negative" salt balance the conditions of osmotic imbalance favouring heat cramps must exist. If the salt deficit is not corrected either by physiological adjustment or by dietary intake, there ensues a strong liability to the syndrome described by McCance (1936) as well as to heat cramps when working in the heat.

On the basis of present knowledge it seems desirable to continue the generally accepted policy of salt supplementation for men exposed to heat. For it cannot be assumed from the available data that the general condition on a low salt diet improves when salt balance is eventually re-established. Taylor and others (1943) have found a marked deterioration both in working ability and in postural adjustment on a salt intake of $6 \mathrm{~g}$. a day compared with $15 \mathrm{~g}$. when subjects were tested in the hot room daily over periods of two or three days. Another consideration in favour of a relatively high salt intake is the likelihood that large individual differences exist in the ability of the sweat gland and the kidney to restrict salt losses. Adolph (1947) has drawn attention to the strikingly greater sweat salt output of some men in desert climates. Ladell and others (1944) make the suggestion that cases of salt deficiency with dehydration (with vomiting and cramps) are found in individuals who habitually excrete sweat of too high salt concentration.

In conditions where men sweat fairly profusely, say at a water output of 51 . a day and over, it would be reasonable to estimate a loss of $3 \mathrm{~g}$. of salt per working hour and about 0.3 to $0.5 \mathrm{~g}$. per hour during recovery and at rest. Near the upper limit of tolerance, i.e., four hours' activity in the heat producing 4.5 litres of sweat, the daily requirement would then be about 20 to $24 \mathrm{~g}$. of salt. This figure is close to the average intake, as actually measured, of men working in tropical climates (Molnar, Towbin, Gosselin, Brown, and Adolph, 1946). It would necessitate in most cases a supplement of about $10 \mathrm{~g}$. to the salt in the usual diet. Methods of administration of salt in industry have been dealt with by Stewart (1945). 


\section{Summary}

The sweat and urinary loss of chloride have been studied in individuals working in hot conditions for short periods.

Acclimatization to heat is only accompanied by a decrease in the chloride concentration of general body sweat if a negative chloride balance is induced by restriction of the chloride intake.

Sweating for short periods (two hours) in unacclimatized subjects brings about a compensatory reduction of urinary chloride manifested after the subject leaves the hot room. This reduction is so great that the total loss of chloride may be less on days on which sweating occurs than on the control days.

Attention is drawn to the limitations to the use of sweat collected in arm bags as a method of assessing the bodily salt balance.

The bearing of these findings on the desirability of supplementing the salt intake in the diet is discussed.

Our best thanks are due to the subjects, and in particular to Mr. R. Baldock for cooperation in these investigations.

\section{- REFERENCES}

Adolph, E. F., ed. (1947). " Physiology of Man in the Desert." New York.

Barcroft, J., Meakins, J. C., Davies, H. W., Scott, J. M. Duncan, and Fetter, W. J. (1923). Phil. Trans. Roy. Soc. B 211, 455.
Bazett, H. C., Sunderman, F. W., Doupe, J., and Scott, J. C. (1940). Amer. J. Physiol., 129, 69.

Belding, H. S., Darling, R. C., Griffin, D. R., Robinson, S., and Turrell, E. S. (1945). In "Clothing Test Methods", edited by $\mathbf{L}$. H. Newburgh and Milton Harris. Michigan.

Black, D. A. K., McCance, R. A., and Young, W. F. (1944). J. Physiol., Lond., 102, 406.

Conn, J. W. (1949a). Advanc. intern. Med., 3, 373. (1949b). Arch. intern. Med., 83, 416.

-, and Johnston, M. W. (1944). J. clin. Invest., 23, 933.

- - — L Louis, L. H. (1946). Ibid., 25, 912.

Dill, D. B., Jones, B. F., Edwards, H. T., and Oberg, S. A. (1933). J. biol. Chem. 100, 755 .

Ladell, W. S. S. (1945). Brit. med. Bull., 3, 175. (1949). Lancet, 2, 836.

-, Waterlow, J. C., and Hudson, M. F. (1944). Ibid, 2, 491, 527.

Lee, D. H. K., and Mulder, A. G. (1935). J. Physiol., Lond., 84, 410.

, Murray, R. E., Simmonds, W. J., and Atherton, R. G. (1941). Med. J. Aust., 2, 249.

McCance, R. A. (1936). Lancet, 1, 643, 704, 765, 823.

Molnar, G. W., Towbin, E. J., Gosselin, R. E., Brown, A. H., and Adolph, E. F. (1946). Amer. J. Hyg., 44, 411.

Moreira, M., Johnson, R. E., Forbes, A. P., and Consolazio, F. C. (1945). Amer. J. Physiol., 143, 169.

Moss, K. N. (1923). Proc. roy. Soc. B, 95, 181.

Newburgh, L. H. (1949). Editor, "Physiology of Heat Regulation and the Science of Clothing." Philadephia and London : and the Science of

Robinson, S. (1949). In "Physiology of Heat Regulation and the Science of Clothing ", edited by L. H. Newburgh. Philadelphia.

- Kincaid, R. K., and Rhamy, R. K. (1950). J. appl. Physio'., 2, 399.

- - - (1950). Ibid., 3, 55.

Turrell, E. S., Belding, H. S., and Horvath, S. M. (1943). Amer. J. Physiol., 140, 168.

Stewart, D. (1945). British Journal of Industrial Medicine, 2, 102.

Talbott, J. H. (1935). Medicine, Baltimore, 14, 323.

Taylor, H. L., Henschel, A. F., Mickelsen, O., and Keys, A. (1943). Amer. J. Physiol., 140, 439.

Van Heyningen, R. E. (1951). "Adaptation of Men to Hot Climates with Reference to Sweat Gland Activity and Sweat Composition". D.Phil. Thesis, Oxford.

Weiner, J. S. (1945). J. Physiol., Lond., 104, 32.

—, and Van Heyningen, R. (1949). Nature, Lond., 164, 351. 